\title{
Response to the Twemlow Paper
}

\author{
Alvin H. Lawson, Ph.D. \\ California State University, Long Beach
}

\begin{abstract}
Stuart Twemlow's discussion would be strengthened by a familiarity with the birth memories hypothesis, a testable theory that views unidentified flying object (UFO) abduction claims as fantasies originating in perinatal experiences. This paper describes the birth memories hypothesis and provides evidence that near-death experiences, out-of-body experiences, shamans' trances, and similar events are abduction analogs also originating in birth memories. I critique Twemlow's remarks on abductions, "fantasy-prone" witnesses, and the positive or negative quality of abduction analogs; examine several long-standing puzzles about abductions that the birth memories hy. pothesis resolves; and review the omnipresence of birth-related imagery in cultural and artistic fantasy worldwide. This paper ends with a discussion of fetal experiences and their implication for the interpretation of "good" and "bad" UFO abductions, near-death experiences, and other analog fantasies.
\end{abstract}

Stuart Twemlow's paper offers some significant insights, especially his view that supposed unidentified flying object (UFO) abduction experiences have extensive parallels with near-death experiences (NDEs), and his implied conclusion that both phenomena are analogous nonphysical events. I am gratified when any researcher embraces a psychological interpretation of abduction claims, though Twemlow's murky jargon for his view is "an integrated psychodynamic perspective." I must point out, however, that Twemlow's discussion of abductions, "fantasy-prone" witnesses, and the debate about the positive or negative character of abductions and NDEs would be much less confused if he adopted the birth memories hypothesis as proposed by

Alvin H. Lawson, Ph.D., is Professor of English, Emeritus, at California State University, Long Beach. Reprint requests should be addressed to Dr. Lawson at 5861 Huntley Avenue, Garden Grove, CA 92645. 
Willifred McCall and myself to clarify these and other abductionrelated matters (Lawson, 1989).

\section{The Birth Memories Hypothesis}

In 1977 , in an attempt to prove whether abductions were physically real, McCall and I planned and carried out the "imaginary abductee" study. We hypnotized 16 volunteers who knew nothing about UFOs and gave each an imaginary abduction. We had assumed that they would merely parrot superficial UFO data from movies and the media, and that their predictable narratives would establish by contrast the reality of the entire UFO phenomenon. But not only were imaginary narratives identical in content with "real" ones, they echoed unusual events from unpublished abduction reports our subjects could not possibly have known about. The "imaginary abductee" study proved beyond question that "real" abduction claims are fantasies-that is, mental and not physical events (Lawson, 1980).

In time I found that the structure and content of abduction narratives parallel several well-established fantasies/hallucinations, including NDEs, shamans' trances, and especially psychiatrist Stanislav Grof's (1976) drug-induced hallucination experiments, during which subjects' birth memories were revivified with the aid of lysergic acid diethylamide (LSD) and other hallucinogens. I also found that the dominant images in abduction fantasies are perinatal-that is, associated with the witnesses' own prenatal, natal, or postnatal birth events. Birth data abound in all abduction reports, averaging more than 17 percent, or one in every six significant images, events, and descriptions in an abductee's narrative. The birth echoes include accounts of fetal aliens, womblike chambers, cervical doorways, vaginal tunnels, umbilical tubes, "big rooms" reflecting feelings of the spacious delivery room after vaginal compression, and a variety of other natal imagery.

The Lawson/McCall program of hypnotic research into abduction claims led to the birth memories hypothesis:

A UFO abduction is an involuntary fantasy of images and events unconsciously based on the witness' own perinatal memories. During the abduction fantasy, revivified birth events symbolically become one or more abduction images or events: the womb = the UFO; the fetus $=$ alien beings and also the witness; the dilating cervix $=$ UFO doorways; the vaginal passage $=$ tunnels or passageways; the comparatively bright delivery room = intensely bright UFO interiors; delivery room postnatal checkup and bath = intrusive probing by alien 
examiners; the parent-infant non-verbal bonding experience $=$ the aliens' "messages," etc. Because of the abduction's peak experience intensity, sequential structure, and surreal qualities, the witness may interpret the fantasy as an actual Close Encounter with extraterrestrial creatures. But like analogous mental phenomena such as near-death experiences, shamans' trances, and hallucinations, an abduction is demonstrably a rare but normal psychological delusion. (Lawson, 1993, p. 51)

Like all revolutionary concepts, our birth-oriented ideas may seem absurd at first, but the birth memories hypothesis is not just another wild theory about Little Gray (fetus-like) Men in flying saucers. The birth memories hypothesis is uniquely important because it makes the study of UFO abduction reports scientific by providing the first verifiable explanation for abduction claims. The birth memories hypothesis is verifiable because it is testable; that is, objective investigators can determine whether our theory is true or false by replicating our experiments (Lawson, 1989). Identical results would verify the birth memories hypothesis, whereas contradictory results would show it to be false.

We have been waiting for more than a decade for formal replication of our work. Abduction proponents such as Budd Hopkins $(1981,1987)$, David Jacobs (1992), and Ray Fowler (1979, 1982, 1990) believe that "alien geneticists" are experimenting with abductees' reproductive organs and creating hybrid babies. I argue that these true believers are mistaking the perinatal imagery from their subjects' abduction fantasies for alien genetic activity, and so have merely updated the hoary (though perinatal) myth of the "changeling." Hopkins and his followers have been among our most outspoken critics, and yet they have ignored the rapidly proliferating mass of birth data their own books and articles have added to abduction case files. Ironically, every time they regress a UFO abduction "victim" (their term), their uninformed activities inadvertently replicate our "imaginary abductee" study and validate the perinatal tests I devised for the birth memories hypothesis (Lawson, 1989).

Since the modern birth of UFO studies in 1947, very few testable ideas about UFOs have even been proposed, though dozens of untestable theories have come and gone. The extraterrestrial hypothesis, for instance, is not falsifiable; that is, its falseness is impossible to establish because one cannot prove a negative assertion, such as that aliens are not visiting us. On the other hand, proving the validity of the extraterrestrial hypothesis would require the cooperation of at least one actual extraterrestrial. Thus the extraterrestrial hypothesis remains only one of many possible but untestable, and therefore 
scientifically less interesting, speculations about the UFO abduction enigma.

Twemlow came close a couple of times to endorsing a perinatal hypothesis; once, for instance, in a discussion of NDEs and Wilfred Bion's "catastrophe" hypothesis:

NDEs do not represent so much an experience of imminent physical death, but are what Wilfred Bion (1963) called experiences of catastrophe: a nameless dread or sense of panic as if one's sense of self . . . is in danger of being destroyed. Bion believed that this sense of catastrophe remains at the core of existence throughout life. ... The positive NDE can be understood as one manifestation of such faith. . . UFO abductees are much more likely to remember their experiences as abusive or judgmental.

Twemlow's discussion made Bion's concept of a "sense of catastrophe" seem parallel with Grof's drug-induced hallucination experiment data, which support the idea of a catastrophic past event in human lives but identify it as the remembered trauma surrounding the birth experience. Grof's studies of subjects' revivified perinatal events routinely involved, along with "good" womb memories, the late-stage fetus in explosive, volcanic emotional states that remain as a permanent memory of a life-and death struggle against suffocation and the prolonged ordeal of a normal birth.

Twemlow's second brush with a birth-oriented perspective started with his cogent skewering of Jacobs' gullible book advocating abductees claims, Secret Life (1992):

Jacobs (1992) reviewed a variety of [alternative] explanatory theories, with obvious bias. He dismissed various explanations because, according to him, they failed to account for the similarity of phenomenological detail and the extraordinary "convergence of abductee narrative across all cultural boundaries"... Jacobs' statement that there is lack of strong personal content in abduction accounts is simply false.

Twemlow then suggested that abductions, NDEs, and other out-ofbody experiences are traceable to nurturing events that are a universal part of all human perinatal development:

Human beings all have basic similar mental mechanisms and especially similar basic defenses. It seems highly likely that such intensive psychological experiences tend also to be rather similar, since many of these primitive anxieties had their template laid down very 
early in nurturing experiences that do not vary greatly between cultures.

For whatever reasons, Twemlow did not develop these perinatal parallels further, though as I will show, a birth-related approach is his only hope of avoiding the confusions that plague UFO abduction proponents.

\section{UFO Abductions and Abduction Analogs}

Our birth-related research is significant for Twemlow and other abduction/NDE researchers in part because it sheds light on many unknown or poorly understood characteristics of the UFO abduction phenomenon. It also shows that both imaginary and "real" abduction claims have extensive parallels with drug-induced hallucinations, NDEs, out-of-body experiences, shamans' trances, Little People visitations, Christian visions, and similar mental phenomena. These fantasies/hallucinations share so many qualities with UFO abductions that I have long thought of them as "abduction analogs."

Abduction analogs range from the clinically familiar to the occult, and include a variety of states of consciousness, from normal to mystical. McCall and I studied some of these with a hypnosis series modeled on the "imaginary abductee" experiments that compared data from "real" and imaginary NDEs, Christian visions, and other analogs. Our sample was small, but results supported the view that the imaginary and "real" analogs have common psychological origins.

Abduction analogs have comparable sequences, a "peak" experience intensity, and similar imagery, much of it birth-oriented. Reported images and events (not always in the same order) include: loss of control, bright light, paralysis, being lifted by light, a physical or moral examination, image constants, starry skies, messianic feelings, an aftermath of varying difficulty, and a sense of ineffability about the whole event. Specific birth imagery and incidents are abundant in abduction analogs: umbilical pain, breathing problems, head and body pressure, tunnel or tube imagery, cervical doorways, vaginal passageways, big rooms, amniotic (clear) chambers, "white" sound humming, strange tastes or odors, body size change, body dismemberment (as during vaginal struggles), a life review (an echo of the physical examination at birth), messages (mostly non-verbal or tactile and related to bonding), apocalyptic events, and amnesia (Lawson, 1993). 
One important parallel among all abduction analogs is that their sequences of events typically progress toward increasingly intense levels of experience, as from bright lights to disturbing imagery and finally terrifying, ecstatic, or ineffable sensations. Any such sequence could help give the percipient the illusion that the event was a purposefully structured physical rather than psychological experience. Since some analogs approximate the emotional and metaphysical intensity of a spiritual rebirth, a religious vision, or other peak experience, they may produce longterm changes in a witness's behavior. Such "reborn" aftermaths are particularly evident in witness reactions to NDEs and UFO abductions, one reason why witnesses often find them unforgettable.

Yet sequences have been connected with brain function rather than external stimuli. Researchers have found a drug that replicates the hysterical condition known as panic attack-itself an analog-by triggering in subjects the same series of events every time. If a sequence originates in brain chemistry, it may not need any external physical cause, more reason to conclude that UFO abductions and its analogs are psychological events.

All abduction analogs contain image constants, or recurrent shapes, colors, motions, and events described by subjects who have spontaneous or induced hallucinations. These take various forms: geometric, such as lattices, zigzags, and battlements; spirals, such as tunnels and webs; and consistently bright and intense colors and lights. Types of motion include rotating, explosive, pulsing, and random. Event constants originate in the witness's memory (Siegel, 1977a).

Image constants relate to our discussion because they are psychological patterns that may manifest themselves as illusions of intense nightlights, rapidly rotating disks, and especially as geometric surface designs. Witnesses may interpret rectangles or circles hallucinated on a bright light source as a UFO with windows or doors. Such report data make it all but certain that some UFO nightlight sightings involve fantasies or hallucinations.

Because they appear in the artwork of cultures the world over, image constants are thought to be archetypal. Examples include the battlement, zigzag, and lattice patterns in Amerindian artifacts; the dreamy, floating perspectives in surrealist paintings; and the pulsating and explosive shapes and colors in art by schizophrenic patients.

Psychologist Ronald Siegel, however, linked some image constants not with archetypes but, prosaically enough, with the anatomy of the human eyeball. He said that during appropriate conditions, such as hallucinations and dreams, the eye produces visual impressions of its 
own inner structure, which the brain then interprets as one or another constant. Thus lattices, battlements, and similar geometric patterns may originate in the neat array of tiny rods and cones on the retinal surface, and funnel-like webs and spirals may reflect the eyeball's rear area where the optic nerve exits (R. Siegel, personal communication, November, 1977; see also Siegel, 1977a, 1977b; Siegel and West, 1975).

Tunnels and tubes are among the most numerous image constants in abduction analogs, and I think they relate directly to perinatal events. They often take the form of various sized beams of light: a large (vaginal) tunnel of light may levitate a witness aboard a UFO, and a small (umbilical) beam may be used by aliens as a body probe. Similar tunnels and tubes were described by three imaginary abductees during their boarding (Lawson, 1980, p. 217-218):

IMAGINARY SUBJECT \#1: A long tube came out of [the UFO], and it was about two feet above me.... And this long cylinder-like tube came down. It was gray and ... was like all colored lights inside of it. ... I seem to be floating for a second, and-then I was inside.

IMAGINARY SUBJECT \# 3: . . gentle suction . . . it just sort of drew me up into it, sort of through the bottom . . . like some sort of tunnel of air and light, drawing me up inside of it. . . . I'm inside of a tube when I first come in.

IMAGINARY SUBJECT \#4: I was pulled in . . a particle of dust into a vacuum cleaner. I mean, I'm just suddenly there.

Narrative descriptions by percipients of different analogs are often nearly identical, particularly when they deal with birth-related imagery and events. For instance, abductees and other witnesses frequently describe passing through a narrow doorway into a big room or vast hall, a parallel with the fetus's sudden relief after the stress of normal delivery. Echoes of the vaginal tunnel and delivery are readily found. The three excerpts below are from different analogs: an imaginary UFO abduction described by my subject \#8, a "real" UFO abduction reported by a witness in a 1976 Kentucky case, and a drug-induced hallucination described by one of Siegel's subjects. Yet all the witnesses describe an identical birth-fantasy scene: they are lying at the bottom of a huge tube-shaped chamber or big room, facing upward (Lawson, 1980, pp. 221):

IMAGINARY UFO ABDUCTION: They seem to have . . brought me to this ... it almost seems like a tube. The ceiling is about 20 feet high. And I seem to be about three feet from the floor. 
"REAL" UFO ABDUCTION: I can see sky up there! I'm looking up through rocks!...It's a volcano, maybe.... Like a long tube ... jagged.

DRUG-INDUCED HALLUCINATION: It's sort of like a tube, like I sort of feel ... that $\mathrm{Im}$ at the bottom of a tube looking up. ... You can see the [screens] and imagery converging with a point in the center.

Big rooms are plentiful in analogs. A high-domed chamber with circular surrounding windows, looking a lot like the interior of a UFO, was sketched by one of Siegel's drug-induced hallucination subjects after ingesting a psychoactive stimulant.

Parallel events are also common. One of the most significant of these occurs when an NDE or drug-induced hallucination percipient suddenly changes from an observer to a participant and then is elevated by a column of light, whisked through an open passageway, or is otherwise "abducted" by his or her own hallucinatory imagery. This abduction-like event occurs to some degree in all abduction analogs: the floating out of body that occurs explicitly in drug-induced hallucinations and normally initiates NDEs and other out-of-body experiences; the shamans' skyward flight in trance; or a witness's sinking into an underground cavern during an encounter with Little People.

As with UFO abductions, data about the nature and reality of analogs are anecdotal rather than strictly scientific, and we must look for similarities and differences in our attempts to understand them. Kenneth Ring (1992) cited numerous and extensive UFO abduction/NDE parallels, although he did not dwell on other analogs. Siegel (1977a) has shown that hallucinations accompanying painful migraine headaches produce many of the same image constants present in abduction analogs, unquestionable evidence of a common origin in the physiology and/or psychology of the brain.

Questions remain. A psychological hypothesis about UFO abductions and their analogs seems to me to be unavoidable, but one may wonder why the various analogs differ in so many minor ways. I suggest that some differences may be apparent only. Much of the research into neardeath and out-of-body experiences and other supposedly fringe areas of psychology has been about as spotty and amateurish as that into UFO abductions. What seem to be dissimilarities may result from the varying methodologies, aims, and professionalism of investigators.

Remember also that there are no proven dual- or multiple-witness abductions on record, in which percipients share the same experience in identical ways. Instead, each alleged abductee always describes a 
separate, distinct series of events, without a detailed and mutually verified involvement with co-abductees, conclusive evidence that UFO abductions are wholly subjective events. Similarly, there are no dual or multiple witnesses to hallucinations, NDEs, shamanic trances, or any other analog. Like UFO abductions, abduction analogs are all in the mind.

It is certain that a videotape of someone in bed having a near-death experience would not show us angels or any dearly departed; nor would a video of an abductee's bedroom abduction fantasy show any Little Gray co-stars. Alien-genetics proponent Jacobs tried to record a witness's midnight abduction, but his videotape only showed the putative abductee carefully turning off the taping equipment in the wee hours, after which, she insisted (and Jacobs believed!), she was abducted (Jacobs, 1992).

In the continuing absence of unambiguous physical evidence for the extraterrestrial hypothesis, the "imaginary abductee" experiments and supporting data should compel such informed and comparatively objective observers as Twemlow to agree that UFOs, aliens, and the rest of the abduction lore are fantasies-mental, not physical, eventsand further, that abduction analogs such as NDEs and out-of-body experiences are not exotic occult or paranormal happenings but psychological experiences, contemporary examples of the immortal continuum of human literary, metaphysical, and folk traditions.

\section{Abduction Analogs and Human Fantasizing}

Twemlow apparently agrees with observers who assert that most abductees, along with NDE and other analog witnesses, are normal but "fantasy-prone" individuals who are "highly hypnotizable [and] highly imaginative." This view of abductees is not consistent with our experience. McCall and I found that "real" abductees were generally poor hypnotic subjects, and their responses were often vague and even sluggish. McCall often had to dig information out of them by laborious and repeated questioning, sometimes for a half hour or more, before they opened up.

We thus expected our imaginary abductees to need much prompting, and accordingly we prepared our first interrogation form with many specifics about UFOs, entities, and typical onboard events. But these leading questions were never asked because the imaginary subjects, who had been selected in part for their high imaginative potential, almost always went immediately into deep hypnosis and responded to 
questions with fluent and detailed narratives. Another group of subjects we worked with, hoaxers, were also excellent hypnotic subjects who went easily into trance and were almost always specific and fluent, often to the point of glibness. Because of these hoaxers, we learned to interpret results from hypnosis sessions cautiously.

For these and other reasons, we believe that subjects who are readily hypnotized and who give fluent and highly detailed narratives are more likely than not to be fantasizing and/or fabricating. Conversely, we conclude that those witnesses who are relatively poor hypnotic subjects and whose narratives are hesitant and sparsely detailed probably have had an actual, spontaneous perinatal abduction fantasy/ hallucination. We are certainly very skeptical of the endless parade, no doubt soon to number in the thousands, of voluble deep-trance or even nonhypnotized "abductees" promoted by alien-genetics proponents.

I believe that the disparities in imaginative potential between "real," imaginary, and hoaxing UFO abduction witnesses can be explained by reference to perinatal memories. The proliferating discoveries of researchers in the new disciplines of neonatology and perinatal medicine continue to shed light on birth experiences. Our perinatal approach has helped me resolve many persistent mysteries about UFO abductions that have stumped other UFO researchers for many years. Three of these mysteries are closely related, and they shed light on the aspects of Twemlow's paper under discussion: (1) the enigmatic "trigger" for UFO abduction fantasies, (2) the "repeater problem," or reports by abductees of ongoing UFO contact, and (3) the high numbers of supposed "unimaginative abductees" among UFO abduction claimants.

\section{The Stimulus for UFO Abduction Fantasies}

For true believers, the matter is perfectly clear: abductions are physical events, and they must be caused by aliens; because what else could stimulate a UFO abduction experience in an otherwise normal individual? This seemingly intractable mystery has resisted explanation for decades. But I think I have found the abduction "trigger" in the therapeutic nature of revivified perinatal memories.

The stimulus that initiates presumed UFO abduction events is implicit in the provocative conclusions of Arthur Janov (1973) and other Primal Rebirthing specialists. Janov is one of several highly original professionals in a variety of disciplines whose work has incidentally 
provided evidence supporting the birth memories hypothesis. Janov asserted that the seeds of neurosis lie in what are remembered as traumatic perinatal events, and that the deliberate or involuntary revivification of an individual's birth memories results in a therapeutic, and thus desirable, discharge of neurotic tensions.

If Janov is right, the trigger for a UFO abduction is the witness's unconscious but compulsive need to relive his or her own birth experience. A UFO abduction fantasy, then, is what a witness spontaneously experiences in the few minutes to an hour or so of his or her birth revivification. It is usually an involuntary perinatal fantasy/ hallucination, during which birth memories assume the depersonalized and fantastic, though in contemporary terms more acceptable, form of an abduction by alien beings. In former times, such fantasies focused on demons, angels, or spirits. A UFO abduction is merely the current "reasonable" mythological vehicle.

A perinatal neurotic's abduction fantasy can be facilitated by fatigue, monotony, or isolation. UFO abductions often occur when the witness is driving on a deserted highway after a long day, or, increasingly often, is in bed and perhaps just at the point of hypnagogic or "twilight" sleep. These situations involve trance states during which an individual's rebirth compulsion may initiate a spontaneous UFO abduction fantasy.

Why should Janov's rebirth fantasies necessarily take the form of UFO abductions? They may not always do so. Depending on circumstances and the percipient's expectations, a particular perinatal fantasy could manifest itself as an NDE, an out-of-body experience, a shaman's trance, or any of a dozen other abduction analogs. A neardeath experience is obviously more likely to occur to someone who is seriously ill and in a hospital bed; a shaman's vision usually follows an expectant hallucinatory ritual; and UFO abductions frequently occur during lonely late-night drives in the boondocks, or when twilight sleepers have a deep but unconscious need to be "contacted."

So why are there not many more reports of UFO abductions, NDEs, and other analogs? Well, there are undoubtedly thousands more such experiences than we ever hear about, which explains why McCall and I found all the UFO abduction cases we needed with just an advertisement or two and by word of mouth. Although the Center for UFO Studies was aware of the reluctance of people to report a UFO abduction, it still badly underestimated their true numbers. Now, after four decades of publicizing UFO myth and lore, the media receive scores of abduction claims following every UFO news story or feature. A booth 
set up at a swapmeet or busy mall can collect a dozen raw and unreported abduction stories or other abduction analogs any weekend. Janov's neurosis-driven birth fantasies are apparently helping to stabilize the populace's mental health, and they are also the source of new and, as I will show next, ongoing contact fantasies as well.

\section{The "Repeater Problem" and Birth Memories}

Janov's therapeutic view of birth memories helps demystify another longstanding problem, one that troubles even UFO abduction true believers: the disconcerting tendency of witnesses to claim repeated UFO contacts or sightings. I should point out that an understanding of the reason for "repeater" abductees also illuminates claims of recurrent NDEs, out-of-body experiences, and other analogs.

How should we view "repeater" abductions? One's initial reaction is to dismiss them posthaste, and, since the witness's credibility seems lost forever, the original report as well. But that would be rash, because Janov's theory, in conjunction with a little perinatal knowledge, offers a simple and persuasive explanation.

Whether perinatal events have been "good" or "bad," a subject may unconsciously wish to relive them-repeatedly. Each UFO abduction/ birth fantasy may help the individual gradually resolve painful early memories; or perhaps it is emotionally rewarding or simply fun to do so. Such motivations help explain UFO abduction repeaters.

The 1973 Pascagoula, Mississippi, abduction of Charles Hickson and Calvin Parker is instructive. In his book, UFO Contact at Pascagoula (Hickson and Mendez, 1983), Hickson wrote that three months after the initial report, stressed by media harassment, he sought a bit of solace by going hunting alone. He stopped for lunch in an isolated spot and was lying back against a rock (remarkably, this was Hickson's alleged exact body position while he was held in mid-air by two entities inside the UFO) when he suddenly saw, about 75 yards away and in broad daylight, the craft that had abducted him and his fishing pal on the previous October evening. At the same time, he heard, like a radio in his mind, the following message:

We mean you no harm. We mean no one any harm. You may communicate with us later. You have endured. You have been chosen. There is no need to fear, we will communicate again. (Hickson and Mendez, 1983, p. 169)

Then the voice stopped, and the UFO was gone. A month later, at night, Hickson went into his backyard to quiet a hound. He saw 
nothing unusual in the sky, but for some reason he squatted downthat is, assumed the fetal position. Then he heard the voice again:

You must tell the world we mean no harm. Your world needs help. We will help you in the future before it's too late. You are not prepared to understand yet. We will return again soon. (Hickson and Mendez, 1983, p. 182)

If reliving birth memories is truly therapeutic, why wouldn't a second, third, or fiftieth birth/abduction fantasy be healthy for Hickson, or for Betty Hill, Whitley Streiber, Betty Andreasson, and all the other witnesses who have reported recurrent "close encounters"? Indeed, Andreasson's interminable abduction stories (Fowler, 1979, 1982, 1990) suggest an obsessive need for repeated perinatal therapy. Her extreme example helps account for the neurotic eagerness of several supposed UFO abduction "victims" who were reportedly hypnotized by Hopkins and Jacobs 30 times or more (Jacobs, 1992).

On the day Hickson went hunting, he felt particularly depressed by the cumulative effects of the nervous breakdown of his buddy Parker and the family turmoil caused by the continuing public controversy over his abduction claims. Then came the sighting and the ensuing message, which Hickson felt was enormously comforting, as he wrote: "I seemed to be relieved of a terrible strain ... the fear had been taken away" (Hickson and Mendez, 1983). Hickson experienced relief after great anxiety, as if an enormous burden had been lifted from him, an emotional pattern not unlike the relief immediately following the physical and psychological stress of vaginal birth. His backyard UFO sighting a few weeks later was not merely therapeutic; Hickson was reborn as a UFO activist:

Since that day I have felt obliged to go to the many places I have been and tell what happened to Calvin and me ... hoping it might someway prepare the people of the world for the things that will come in the future. (Hickson and Mendez, 1983, p. 182)

Many proponents are embarrassed by repeater abductees, whom they think are hoaxing. They believe that UFO abductions involve genuine alien craft that would revisit a witness only about as often as a bolt of lightning. Some repeaters may be hoaxers, though it is hard to know how many, since their deliberately fabricated (that is, fantasized) narratives employ the same perinatal imagery and events as other UFO abduction claims. The frequency of "real" abduction fanta- 
sies is unknown, but they are probably as common as bad nightmares, which may occur weekly or as rarely as once or twice in a lifetime.

\section{The "Unimaginative Abductee" Syndrome}

Despite Janov's conclusions, the compulsion to reexperience one's own birth in fantasy may not always need a neurotic trigger. A normal imagination and a healthy curiosity about one's own physiological origins may be sufficient. Yet investigators have long observed that many abductees seem unimaginative, and they have seized on that fact to argue for the credibility of particular cases: this witness, they say, couldn't be hoaxing because he or she lacks the imagination. A judicious reading of the narrative transcripts of such typical abductees as Carl Higdon, Hickson and Parker, and Sandy Larson shows that many abduction witnesses fit this mold.

I believe that it is the tiny minority of persons who by nature or nurture live their lives without adequate fantasizing whose psyches, neurotic or normal, most need a therapeutic birth revivification fantasy. It follows that they are more likely than the rest of us to have a "real" UFO abduction or other birth fantasy analog, spontaneously and therefore involuntarily.

This view helps explain the numbers of UFO abductions, NDEs, Marian visions, and other analog fantasies claimed by children or members of stereotypically undereducated, illiterate, or indigent classes throughout the world. Skeptics tend to discount abduction reports from such persons, though they might take a witness with a $\mathrm{Ph}$.D. seriously. But few credible professors claim to be abductees or to have chatted with the Virgin Mary, largely because their lives include a healthy variety of regular fantasizing activities: reading, films, art, and miscellaneous cultural events. It is not a matter of intelligence, but of the repression of normal human potential. Those on the lower end of the socioeconomic scale tend to have a more limited range of experiences than other people-socially, intellectually, psychologically, educationally, and otherwise. It should not surprise us if neurotic or exceptionally unimaginative individuals are more frequently found among poorer populations worldwide.

\section{Abductions, Analogs, and Fantasy}

The interconnections between abduction analogs and perinatal memories result from the nature of human fantasizing and its aesthetic, cultural, and psychological effects. Fantasy as a genre is the most 
undisciplined segment of traditional art and culture. It has visionary, irrational, and dreamlike qualities that distinguish it from more realistic and restrained products of the human imagination. As I have said, a particularly important characteristic of fantasy, in literature, art, film, or belief, is that for reasons unknown it nearly always displays explicit or symbolic perinatal imagery and events. Fantasy's linkages with birth memories help account for its unusual character and enduring popular appeal.

Nearly all literature about UFOs, aliens, or space travel is fantasy; such material deals with "far out" rather than mundane subject matter, utilizing magical or supernatural events and suprahuman characters. Most fantasy fiction consistently displays literal or allegorical imagery involving perinatal memories, often in great abundance. Fantasy can be distinguished from pure science fiction because the latter's focus is ultimately on high-tech, nuts-and-bolts realism, with comparatively little imaginative wildness. Though there is plenty of gray area between the two genres, science fiction generally employs far less perinatal imagery.

Filmed fantasies, from space epics to tasteless slasher gore, offer a particularly rich display of birth-related events. Sadly, special effects technologies now make it possible for such movies to dwell on graphic birth carnage, closeups of demonic fetuses or other perinatal monstrosities pushing through human flesh or exploding repulsively from abdomens.

Fantasy films tend to have sensational and preposterous plots, yet I believe that their litany of pregnancies, fetuses, problem births, anatomical trauma, deliveries, and rebirths affect audiences more deeply than their storylines. Birth-related imagery is the essence of the fantasy genre, and by viewing such material individuals may passively and perhaps unconsciously relive and so work out their own perinatal anxieties in an entertaining, objective, nonthreatening, and therapeutic context, just as Janov has suggested.

Janov's ideas help explain the continuing popularity of a variety of perinatal phenomena elsewhere in contemporary media. Examples are plentiful. Television soap operas are loaded with daily sagas of pregnancies, miscarriages, abortions, births, illegitimacy, surrogate mothers, and, perhaps above all, sterility. Sensational tabloid headlines focus on bizarre perinatal events, from alien rapists to women who give birth to chickens. And though it is generally unacknowledged, pop/rock music videos contain remarkable amounts of explicit or symbolic birth imagery, and so testify to the omnipresence of perinatal data in worldwide popular culture (Lawson, in press). Birth-related media fantasies run the gamut from subtle to sleazy, but they evi- 
dently provide people with a needed means of coping with disturbing perinatal memories.

A staple of almost all film fantasies is the cataclysmic finale, in which the obligatory mad scientist, his magic formula, and monsteralong with his laboratory, castle, island, entire planet, or whateverare annihilated by a series of titanic though purifying explosions. Grof's (1976) finding that volcanic emotional states are a regular part of birth revivifications supports the view that the explosive endings of fantasy films are symbolic rebirth events that in emotional terms dispose of the old corrupt world and prepare us for a (hopefully) less corrupt new one.

Most people spend a good part of their life in some fantasy activity: reading it, watching it on film, daydreaming, even using it creatively. Fantasizing is one way humans satisfy the normal "birth revivification itch" within us all. Without fantasy, there almost certainly would be many more perinatal neurotics, and therefore more spontaneous UFO abductions, NDEs, and so on.

One consequence of the "unimaginative abductee" syndrome is that abduction claims have lost appeal as a potential subject of scientific study because of the perception that only drunks, lunatics, and similar noncredible witnesses report being abducted. Twemlow implied that a similar reputation afflicts research into NDEs and other abduction analogs.

No responsible investigator should take UFO abductions, NDEs, or other analog narratives literally, but of course that does not mean that these fantasies/hallucinations are inappropriate for serious research. A few psychologists have suggested that some abductees may be victims of childhood sexual abuse, which has already been linked to multiple personality disorder, and "past lives" fantasies and other analogs. Verification of specific cases of abuse has proved difficult, and attempts to investigate it among abductees has met with intense opposition from Hopkins and other proponents of the extraterrestrial hypothesis. Yet objective observers will ultimately see that UFO abductions and their analogs are incompletely understood psychological experiences, which only rigorously scientific psychological investigations will illuminate.

\section{"Positive" and "Negative" Analogs and the Birth Memories Hypothesis}

Twemlow conceded that UFO abductions and NDEs have significant similarities, but he uncritically asserted that they share a major differ- 
ence: that 95 percent of NDEs are "positive" events for experiencers, and that 95 percent of abductions are "negative." Our experience with abductees and other subjects does not support such a polarized assessment. Yet I think I know why Twemlow and many other researchers approach UFO abductions and their analogs in such black-and-white terms.

There has been a decade and more of mulish debate about the presumed positive or negative nature of both UFO abductions and NDEs. Participants have opted for one extreme or the other, and virtually none of them has seen the issue with clarity. The truth is that abductions and their analogs can be both positive and negative, as well as dominantly either one. The alien-genetics proponents who now preside over the UFO abduction establishment have no clue as to why this is, although the perinatal perspectives of the birth memories hypothesis account for it completely. Some brief but necessary background on fetal life and development can demonstrate the facts persuasively.

\section{Theories about Fetal Life}

Psychohistorian Lloyd DeMause (1982) pointed out that there have been several longstanding obstacles to an enlightened view of the fetus. One was Sigmund Freud's conception of birth as a source of "separation anxiety" for the newborn, which implied that fetal life until delivery was peaceful and uneventful. Another was the medical profession's belief, based on a fallacious 1933 study, that incomplete myelination or sheathing of its nerve fibers prevented the fetus from experiencing sensory input, and that the fetus was deaf, blind, and insensitive to pain. This insensient view led to decades of circumcisions and other infant surgery without anesthetics, practices that sadly continued long after it was known that partial myelination merely slows but does not halt nerve impulses.

\section{The Traumatic Womb}

The traditional view of the womb as a peaceful and quiescent "living tomb" is also mistaken; nor does the fetus exactly resemble a mummy, as DeMause showed:

The womb is in fact a very noisy, very changing, very active place in which to live, full of events and emotions both pleasant and painful. 
The fetus during the second trimester, when the amniotic sac is still rather roomy, now floats peacefully, now kicks vigorously, turns somersaults, hiccoughs, sighs, urinates, swallows and breathes amniotic fluid and urine, sucks its thumb, fingers, and toes, grabs its umbilicus, gets excited at sudden noises, calms down when the mother talks quietly, and gets rocked back to sleep as she walks about. Fetal activity patterns are now well studied, particularly since the development of ultrasound techniques. The normal fetus rarely goes $10 \mathrm{~min}$ utes without some gross activity, either with fetal breathing spurts during REM-sleep periods or with other movements. ... The fetus in fact has quite regular activity cycles averaging about 45 minutes, cycles that later in the third trimester can be felt quite accurately by the mother. These fetal patterns become coordinated to some extent with the activity cycles of the mother-evidence that the fetus is quite sensitive to a wide range of the mother's activities and emotions. (1982, p. 253)

In the third trimester the fetus grows increasingly uncomfortable: the womb is crowded, and the placenta becomes less efficient in its functions of nourishment, respiration, and disposal of wastes. DeMause pointed out that, during normal labor and delivery, fetuses suffer from extreme and perhaps prolonged hypoxia or inadequate oxygen levels, sometimes as low as 12 percent, incredible as that may seem, although adults become comatose at less than 60 percent:

The effects on the fetus of this severe hypoxia are dramatic: normal fetal breathing stops, fetal heart rate accelerates, then decelerates, the fetus often thrashes about frantically in reaction to the pain of the contractions and the hypoxia, and soon the fetus enters into its lifeand-death struggle to liberate itself from its terrifying condition .... Yet it is a liberation struggle for all that, and not at all a "separation anxiety" from a comfortable womb. (1982, p. 257)

The extensive parallels between abductees and fetuses include many accounts of late-stage ordeals. A large number of abductees report sensations of choking, suffocation, and severe pressure on their head and body. These are obvious perinatal parallels that many UFO abduction investigators observe and carefully describe in their case reports, but do not comprehend.

DeMause cited birth regression studies with subjects whose narratives, checked against medical records, support the accuracy of specific late-stage birth memories, and he wrote that those memories are vivid and indeed mostly negative:

Every piece of evidence, both obstetrical and clinical, which is added to the growing literature of fetal life confirms the concrete reality of these memories of feelings of pain, fear, and rage as the fetus strug. gles for liberation from the asphyxiating womb. $(1982$, p. 258) 


\section{The Fetal Drama}

DeMause maintained that the realities of prenatal life lead to the "fetal drama," which has extensive and potentially permanent psychological consequences. The earliest tangible reality in the fetus's world is the placental/umbilical complex, on which its survival depends. The cyclical inconsistencies of the maternal system stimulate perhaps the first crucial psychological response the developing human being has yet experienced: fetal anxiety.

DeMause has convincingly analyzed the ambivalent nature of the fetus's prenatal environment: its "positive" aspects originate in what he called the Nurturant Placenta, and "negative" events stem from a seemingly Poisonous Placenta. This ambivalent mix of perinatal experiences is the matrix for the "good" and "bad" memories that emerge later in varying combinations in UFO abductions, NDEs, and other analogs:

Slowly during the second and third trimesters the first structuring of fetal mental life takes place. When the blood coming from the placenta is bright red and full of nutrients and oxygen, it is felt to be coming from what I shall term a Nurturant Placenta and the fetus feels good, but when the blood becomes dark and polluted with carbon dioxide and wastes, it is imagined to be coming from a Poisonous Placenta, and the fetus feels bad and can be seen to kick out at the source of its pain. In the final months before birth, as the fetus outgrows the placenta, the womb gets more crowded and the blood more polluted, and the fetal drama steps up in intensity. I propose that just as the satisfying and grateful emotions associated with the Nurturant Placenta form a prototype for all later love relationships, so, too, the polluting-asphyxiating experiences produce an attitude of fear and rage toward the Poisonous Placenta, which is therefore the prototype for all later hate relationships - whether with the murderous mother, the castrating father, or ultimately, the punitive superego itself. (DeMause, 1982, p. 259)

DeMause has established the significance to the fetus of (1) the major birth organs (placenta, umbilical tube, amniotic sac and fluids); (2) the maternal body and its ingestions, movements, and changing emotional contexts; (3) the fetus's own developmental processes (respiration, waste removal, nutrition, and growth); (4) the anxiety of the final weeks of gestation because of the ambivalently nurturant/poisonous placenta; and (5) the surrounding maternal tissues, the cervical opening, and the vaginal tunnel.

These are the germinal materials of perinatal memories. Late-stage fetuses have often been observed actively feeling their body and the organs and tissues in the womb's darkened environment. That they 
must develop very early a tactile sense of the shape and nature of their own body is clear from a photograph of an hours-old neonate, face-toface with its obstetrician and imitating the doctor by sticking out its tongue. If DeMause is right in concluding that prenatal experiences are prototypes for adult emotional relationships, it is no mystery that they can be recalled or revivified in later life, spontaneously or with the aid of hypnosis or drugs.

\section{Final Thoughts}

One measure of a new theory's value is how much it can explain that previously seemed ambiguous or inexplicable. The fact that the perinatal approach of the birth memories hypothesis offers reasonable explanations for many previously enigmatic questions about UFO abduction claims constitutes a strong argument for its scientific soundness. Although this response has considered only three of the many points in Twemlow's paper, I believe I have argued successfully that a birthoriented perspective can also illuminate enigmatic issues involving NDEs and other analogs.

It seems inevitable to me that near-death researchers will one day embrace the birth memories hypothesis and its inescapable implication that abductions and their analogs are nonphysical, psychological, and essentially mundane, though fascinating, events. Unfortunately, I am still waiting for the first UFO abduction true believer to see the birth memories hypothesis light. Perhaps Twemlow and his fellow analog researchers are made of less obdurate clay.

\section{References}

Bion, W.R. (1963). Elements of psycho-analysis. London, England: Heinemann.

DeMause, L. (1982). Foundations of psychohistory. New York, NY: Creative Roots.

Fowler, R.E. (1979). The Andreasson affair. Englewood Cliffs, NJ: Prentice-Hall.

Fowler, R.E. (1982). The Andreasson affair: Phase two. Englewood Cliffs, NJ: PrenticeHall.

Fowler, R.E. (1990). The watchers. New York, NY: Bantam.

Grof, S. (1976). Realms of the human unconscious: Observations from LSD research. New York, NY: Viking.

Hickson, C., and Mendez, W. (1983). UFO contact at Pascagoula. Tucson, AZ: Wendelle C. Stevens.

Hopkins, B. (1981). Missing time. New York, NY: Richard Marek.

Hopkins, B. (1987). Intruders. New York, NY: Random House.

Jacobs, D. (1992). Secret life: Firsthand accounts of UFO abductions. New York, NY:

Simon and Schuster. 
Janov, A. (1973). The feeling child. New York, NY: Touchstone.

Lawson, A.H. (1980). Hypnosis of imaginary UFO "abductees." In C. Fuller (Ed.), Proceedings of the First International UFO Congress (pp. 195-238). Chicago, IL: Warner.

Lawson, A.H. (1989). A testable theory for UFO abduction reports: The birth memories hypothesis. In D. Stillings (Ed.), Cyberbiological studies of the imaginal component in the UFO contact experience (pp. 125-142). St. Paul, MN: Archaeus Project.

Lawson, A.H. (1993). UFO abductions and birth memories: Scientific proof that close encounters are fantasies. Unpublished manuscript.

Lawson, A.H. (In press). Placental guitars, umbilical mikes, and the maternal rock-beat: Birth fantasies and rock music videos. Journal of Psychohistory.

Ring, K. (1992). The Omega Project: Near-death experiences, UFO encounters, and mind at large New York, NY: Morrow.

Siegel, R.K. (1977a). Hallucinations. Scientific American, October, pp. 132-140.

Siegel, R.K. (1977b). Normal hallucinations of imaginary companions. McLean Hospital Journal, 2, 666-680.

Siegel, R.K., and West, L.J. (Eds). (1975). Hallucinations: Behavior, experience, and theory. New York,, NY: Wiley. 